\title{
Olive oil consumption and risk of breast cancer in the Canary Islands: a population-based case-control study
}

\author{
Purificación García-Segovia ${ }^{1,2}$, Almudena Sánchez-Villegas ${ }^{1}$, Jorge Doreste ${ }^{1}$, \\ Francisco Santana ${ }^{1}$ and Lluís Serra-Majem ${ }^{1,3, *}$ \\ 'Department of Clinical Science, University of Las Palmas of Gran Canaria, Apdo. Correos 550, 35080 Las Palmas \\ G/C, Spain: ${ }^{2}$ Department of Food Technology, Polytechnical University of Valencia, Spain: ${ }^{3}$ Foundation for the \\ Advancement of Mediterranean Diet, University of Barcelona Science Parc, Spain
}

\begin{abstract}
Back ground: Breast cancer mortality and incidence rates in the Canary Islands, and particularly in Gran Canaria, are higher than those in the rest of Spain.

Objectives and design: A case-control study was designed to assess the role of differential fatty acid intakes and olive oil consumption on breast cancer risk in the Canary Islands. The study was conducted between 1999 and 2001, including a total of 755 women: 291 incident cases with confirmed breast cancer and 464 controls randomly selected from the Canary Island Nutrition Survey (ENCA). A semiquantitative food-frequency questionnaire was completed and potential confounders were adjusted using unconditional logistic regression.

Results: Compared to the first quintile of intake, the highest quintile of monounsaturated fat intake was significantly related to a lower risk of breast cancer (odds ratio $=0.52 ; 95 \%$ CI 0.30-0.92). Regarding olive oil, the odds ratio for women in the three upper quintiles of consumption ( $\geq 8.8 \mathrm{~g} /$ day) was 0.27 ( $95 \% \mathrm{CI} 0.17-0.42$ ). Conclusion: Our results support the protective role of olive oil consumption on breast cancer among Canaries women.
\end{abstract}

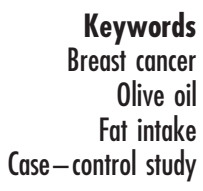

Evidence on dietary fat intake and breast cancer risk come from animal experimentation, ecological and migrant studies, analyses of secular trends and analytical designs such as case-control and cohort studies ${ }^{1}$. Whereas animal studies and international comparisons have suggested a positive association between total fat intake and the risk of breast cancer, particularly among postmenopausal women, longitudinal studies have failed to confirm the deleterious effect of overall lipid intake or specific types of fatty acids on the disease $\mathrm{e}^{2-4}$.

Ecological studies carried out in Mediterranean regions have reported a lower incidence of breast cancer as compared with those from Northern European countries or North America ${ }^{5}$. In spite of the high total fat intake observed in the Mediterranean area, around 30 or $40 \%$ of total energy intake, this paradoxical finding has been explained by its higher monounsaturated/saturated fat ratio $^{6}$. Moreover, several studies performed in Southern Europe have suggested that olive oil, which is the main source of fat used to dress salads and to cook, could exert a protective role on breast cancer ${ }^{7-10}$.

It has been estimated that countries like Greece and Spain obtain approximately 25 and $22 \%$ of total energy, respectively, from vegetable oil consumption, olive oil included $^{11}$. Olive oil is one of the most important features of the Mediterranean diet, which has been postulated as being protective against several diseases including coronary heart disease and cancer. Additionally, olive oil has been associated with lower mortality rates in these regions.

Whereas, breast cancer mortality and incidence are lower in Spain than in other European countries or in the USA, there are alarming rates in the Canary Islands and particularly in Gran Canaria. Thus, the aim of our study was to ascertain the effect of olive oil consumption and different fat intake patterns on breast cancer risk in the Canary Islands, where legislative initiatives and marketing have promoted olive oil consumption in the past 20 years.

\section{Methods}

\section{Case and control assessment}

A case-control study designed to evaluate the relationship between diet and breast cancer was conducted between April 1999 and June 2001 in Las Palmas and Santa Cruz de Tenerife. During the study period, 326 cases (women with a histological confirmed first diagnosis of breast cancer) were collected from the Canary Islands teaching hospitals. We also selected 492 controls among women aged 25-85 years from the Canary Islands Nutrition Survey (Encuesta de Nutrición de Canarias, ENCA) participants. 


\section{Exposure assessment}

A face-to-face interview was conducted in hospital (cases) or primary care settings (controls) by trained personal. A semi-quantitative food-frequency questionnaire (SFFQ, 88 items) was used to assess the usual diet of the participants, total energy and macro- and micronutrient intakes. It was modified from a previously validated questionnaire ${ }^{12}$ to take into account the Canarian diet features.

The food items were categorised into the following groups: cereals and pulses, dairy products, fruits, vegetables, meat, eggs and fish, olive oil and other fats, sweets, nuts, and beverages (including alcoholic drinks). The questionnaire also included data on dressing, cooking and frying fats, to describe the fat intake pattern.

The food composition database was established on the basis of the Spanish food composition tables ${ }^{13}$.

A lifestyle questionnaire asked for sociodemographic variables, chronic diseases, smoking habits (age at onset, age at quitting, number of cigarettes smoked per day, type of tobacco), alcohol consumption (type of beverages, amount of alcohol consumed per day, drinking patterns), physical activity, family history of diseases, menstrual and reproductive events and nutritional beliefs, opinions and attitudes.

Anthropometric variables were collected; women were weighed and measured without shoes and outer clothing.

\section{Statistical analysis}

Women with missing values for the main variables or out of $a$ priori-defined daily energy intake range ${ }^{14}(<1.2 \times$ estimated resting metabolic rate $-\geq 4000 \mathrm{kcal} /$ day) were excluded from the analysis. The final study population was composed of 755 women $\quad$ (cases $=291$, controls $=464$ ).

The nutrient residual model approach ${ }^{15}$ was used to control for the potential confounding effect of energy intake on olive oil consumption and fatty acids intake.
The exposure variables were categorised into quintiles all over the entire study group distribution. The associations were measured fitting unconditional logistic regressions. The lowest quintile of intake was used as the reference category. Odds ratios (OR) and 95\% confidence intervals (CI) were calculated. Models were adjusted for age (years), smoking status (never smoked, ex-smoker and smoker), education level (primary or less, secondary and university degree), presence/absence of benign breast disease, pre- or postmenopausal status, and body mass index $\left(\mathrm{kg} / \mathrm{m}^{2}\right.$, and a quadratic term for body mass index to account for non-linearity). Additionally, every fatty acid intake was adjusted for each other. Finally, we looked for interactions in the olive oil consumption and fat intakebreast cancer associations.

SPSS $^{\circledR}$ version 11.0 (SPSS Inc., Chicago, IL, USA) statistical software was used in the analysis.

\section{Results}

The main characteristics of the participants are shown in Table 1 . The mean age was 55.5 years for the cases and 53.1 years for the controls. There were differences according to menopausal status (postmenopausal women: cases $72.5 \%$; controls $57.5 \%$ ) as well as to benign breast disease history (cases 44.3\%; controls 6.5\%).

Both cases and controls reported a low level of daily physical activity. There was a statistically significant difference in smoking habits, with a higher proportion of smokers in the control group. Energy intake was higher among cases $(2237.7 \mathrm{kcal} /$ day) than among controls (2056.2 kcal/day).

Nutrient intakes were similar for cases and controls (Table 2). Energy intake from total fat ( $40.8 \%$ for cases and $40.9 \%$ for controls) and from monounsaturated fatty acids (MUFA) (16.9\% and 16.7\%) were almost identical.

Table 1 Characteristics of case and control women

\begin{tabular}{|c|c|c|c|}
\hline & Cases $(n=291)$ & $\begin{array}{l}\text { Controls } \\
(n=464)\end{array}$ & $P$ \\
\hline Age (years) [mean $\pm \mathrm{SD}]^{*}$ & $55.5 \pm 11.8$ & $53.1 \pm 11.4$ & $<0.01$ \\
\hline Body mass index $\left(\mathrm{kg} / \mathrm{m}^{2}\right)[\text { mean } \pm \mathrm{SD}]^{*}$ & $29.0 \pm 5.0$ & $28.0 \pm 5.3$ & 0.02 \\
\hline Energy intake (kcal/day) [mean $\pm \mathrm{SD}]^{*}$ & $2237.7 \pm 616.6$ & $2056.2 \pm 620.1$ & $<0.001$ \\
\hline Educational level (\%)† & & & 0.7 \\
\hline Primary or less & 76.6 & 75.9 & \\
\hline Secondary & 13.1 & 15.7 & \\
\hline University degree & 10.3 & 8.4 & \\
\hline Smoking (\%)† & & & $<0.01$ \\
\hline Never & 64.9 & 71.3 & \\
\hline Ex-smoker & 17.5 & 6.9 & \\
\hline Smoker & 17.5 & 21.8 & \\
\hline Physical activity level (\%)† & & & 0.5 \\
\hline Never & 74.9 & 71.6 & \\
\hline Smooth & 22.0 & 24.1 & \\
\hline Moderate & 3.1 & 4.3 & \\
\hline Premenopausal (\%)† & 28.5 & 42.5 & $<0.01$ \\
\hline Benign breast disease $(\%) \dagger$ & 55.7 & 93.5 & $<0.01$ \\
\hline
\end{tabular}


Table 2 Mean and quintiles of total caloric and macronutrient intakes for cases and controls

\begin{tabular}{|c|c|c|c|c|c|c|c|c|c|c|}
\hline & \multicolumn{5}{|c|}{ Controls $(n=464)$} & \multicolumn{5}{|c|}{ Cases $(n=291)$} \\
\hline & \multirow[b]{2}{*}{ Mean $\pm S D$} & \multicolumn{4}{|c|}{ Percentile } & \multirow[b]{2}{*}{ Mean $\pm S D$} & \multicolumn{4}{|c|}{ Percentile } \\
\hline & & 20th & 40th & 60th & 80th & & 20th & 40th & 60th & 80th \\
\hline Energy (kcal) & $2056 \pm 620$ & 1509 & 1844 & 2155 & 2578 & $2238 \pm 617$ & 1663 & 2059 & 2451 & 2800 \\
\hline Carbohydrate $(\mathrm{g})^{*}$ & $211 \pm 45$ & 179 & 202 & 222 & 244 & $213 \pm 47$ & 174 & 203 & 224 & 256 \\
\hline Protein $(\mathrm{g})^{\star}$ & $86 \pm 14$ & 75 & 82 & 88 & 97 & $85 \pm 15$ & 75 & 84 & 90 & 98 \\
\hline Total fat $(\mathrm{g})^{*}$ & $100 \pm 19$ & 85 & 95 & 103 & 113 & $97 \pm 19$ & 82 & 93 & 102 & 113 \\
\hline $\operatorname{MUFA}(g)^{*}$ & $41 \pm 9$ & 33 & 39 & 42 & 48 & $40 \pm 9$ & 33 & 38 & 42 & 47 \\
\hline PUFA $(g)^{*}$ & $13 \pm 4$ & 10 & 11 & 13 & 15 & $13 \pm 4$ & 10 & 11 & 13 & 15 \\
\hline $\operatorname{SFA}(g)^{*}$ & $37 \pm 13$ & 27 & 33 & 38 & 46 & $35 \pm 12$ & 25 & 31 & 37 & 43 \\
\hline Fibre $(g)^{*}$ & $22 \pm 8$ & 16 & 20 & 23 & 28 & $25 \pm 8$ & 17 & 22 & 27 & 31 \\
\hline MUFA/SFA & $1.3 \pm 0.9$ & 0.9 & 1.0 & 1.2 & 1.5 & $1.3 \pm 1.1$ & 0.9 & 1.0 & 1.2 & 1.6 \\
\hline SFA (\%) & 14.8 & 10.0 & 12.6 & 15.5 & 19.3 & 14.6 & 10.4 & 13.0 & 15.4 & 18.4 \\
\hline PUFA (\%) & 5.4 & 4.1 & 4.7 & 5.5 & 6.4 & 5.3 & 4.1 & 4.7 & 5.4 & 6.2 \\
\hline MUFA (\%) & 16.7 & 13.2 & 15.5 & 17.5 & 20.3 & 16.9 & 13.2 & 16.1 & 17.9 & 20.1 \\
\hline Total fat (\%) & 40.9 & 33.8 & 38.8 & 43.2 & 47.9 & 40.8 & 33.9 & 39.1 & 42.8 & 47.9 \\
\hline
\end{tabular}

MUFA, monounsaturated fatty acids; PUFA, polyunsaturated fatty acids; SFA, saturated fatty acids.

${ }^{*}$ Adjusted for energy intake.

OR (95\% CI) for the associations between fatty acid intakes and breast cancer risk are shown in Table 3. Breast cancer and PUFA (polyunsaturated fatty acids) and SFA (saturated fatty acids) intakes were not associated. Linear trends were not statistically significant.

For MUFA, adjusted OR were 1.04 (0.62-1.76), 0.71 (0.42-1.23), 0.80 (0.46-1.36), and 0.52 (0.30-0.92), with only the latter ( 5 th quintile, MUFA intake $>47 \mathrm{~g} /$ day) being statistically significant. A significant linear trend was observed $(P=0.02)$. However, when the model was additionally adjusted for the other dietary fatty acids these associations disappeared.

Olive oil consumption was analysed separately, and we also observed an inverse linear trend with breast cancer risk $(P<0.001)$ (Fig. 1). The OR for women in the three upper quintiles ( $\geq 8.8 \mathrm{~g} /$ day) was 0.27 (95\% CI $0.17-0.42$ ). To assess its cumulative effect, daily consumption was also considered in a quantitative basis, obtaining an OR of 0.97 (95\% CI 0.96-0.98) for each additional gram of olive oil consumption.

\section{Discussion}

A higher consumption of olive oil has been found to be associated with a lower risk of breast cancer. Our results also suggest a dose-response relationship between MUFA intake and breast cancer risk, but not statistically significant after adjusting for the rest of fatty acids in the diet.

Table 3 Association between different types of fats and breast cancer

\begin{tabular}{|c|c|c|c|c|c|}
\hline $\begin{array}{l}\text { Energy-adjusted } \\
\text { fatty acids intake } \\
\text { (quintile) }\end{array}$ & Crude OR $(95 \% \mathrm{Cl})$ & $\begin{array}{c}\text { Adjusted } \\
\text { OR }(95 \% \mathrm{Cl})^{*}\end{array}$ & $P$ trend & $\begin{array}{l}\text { Additionally } \\
\text { adjusted } \\
\text { OR }(95 \% \mathrm{Cl}) \dagger\end{array}$ & $P$ trend \\
\hline \multicolumn{6}{|l|}{ PUFA (g/day) } \\
\hline$<10$ & 1 & 1 & \multirow{5}{*}{0.42} & 1 & \multirow{6}{*}{0.49} \\
\hline $10-11$ & $1.06(0.67-1.67)$ & $1.18(0.70-2.00)$ & & $1.21(0.70-2.09)$ & \\
\hline $11-13$ & $0.89(0.56-1.42)$ & $0.79(0.46-1.37)$ & & $0.83(0.46-1.49)$ & \\
\hline $13-15$ & $0.95(0.60-1.50)$ & $0.89(0.51-1.55)$ & & $0.94(0.51-1.74)$ & \\
\hline$\geq 15$ & $0.87(0.55-1.38)$ & $0.87(0.51-1.51)$ & & $0.88(0.48-1.63)$ & \\
\hline \multicolumn{5}{|l|}{ SFA (g/day) } & \\
\hline$<25$ & 1 & 1 & & 1 & \multirow{5}{*}{0.39} \\
\hline $25-31$ & $0.78(0.50-1.24)$ & $0.82(0.47-1.42)$ & & $0.82(0.47-1.44)$ & \\
\hline $31-37$ & $0.70(0.44-1.11)$ & $0.70(0.40-1.22)$ & 0.18 & $0.73(0.42-1.28)$ & \\
\hline $37-43$ & $0.78(0.50-1.24)$ & $1.09(0.64-1.86)$ & & $1.18(0.68-2.05)$ & \\
\hline$\geq 43$ & $0.60(0.38-0.96)$ & $0.60(0.35-1.05)$ & & $0.66(0.37-1.21)$ & \\
\hline \multicolumn{5}{|l|}{ MUFA (g/day) } & \\
\hline$<33$ & 1 & 1 & & 1 & \multirow{5}{*}{0.07} \\
\hline $33-38$ & $1.15(0.72-1.82)$ & $1.04(0.62-1.76)$ & & $1.14(0.66-1.96)$ & \\
\hline $38-42$ & $0.89(0.56-1.42)$ & $0.71(0.42-1.23)$ & 0.02 & $0.80(0.45-1.40)$ & \\
\hline $42-47$ & $1.06(0.67-1.68)$ & $0.80(0.46-1.36)$ & & $0.93(0.52-1.67)$ & \\
\hline$\geq 47$ & $0.95(0.59-1.51)$ & $0.52(0.30-0.92)$ & & $0.61(0.34-1.11)$ & \\
\hline
\end{tabular}

OR, odds ratio; $\mathrm{Cl}$, confidence interval; PUFA, polyunsaturated fatty acids; SFA, saturated fatty acids; MUFA, monounsaturated fatty acids . *Logistic regression, adjusted for age, smoking, body mass index (BMI) and quadratic BMI, menopausal status and benign breast disease. †Additionally adjusted for all other variables shown in the table. 


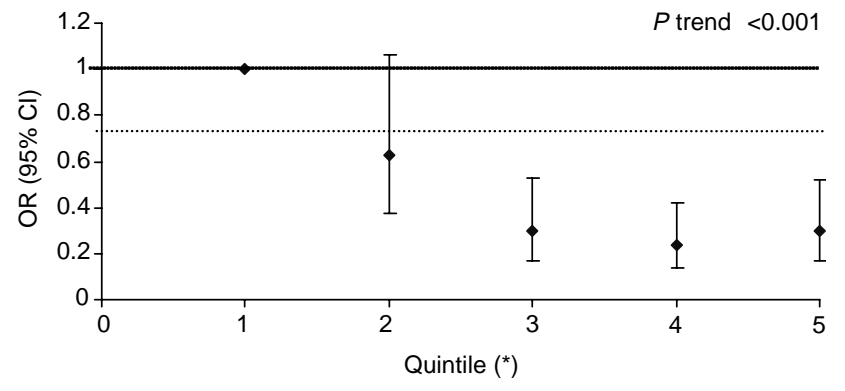

Fig. 1 Odds ratios (95\% confidence intervals) for quintile of energy-adjusted olive oil consumption adjusted for age, smoking status, education level, benign breast disease, menopausal status, body mass index (BMI) and quadratic BMI. *Quintile (g/day): $1=\leq 3.2 ; 2=3.3-8.7 ; 3=8.8-16.0 ; 4=16.1-27.4 ; 5>27.4$

Epidemiological studies have frequently failed to find a relevant association between total or different type of fat intakes and risk of breast cancer ${ }^{2-4}$. It has been argued that an extremely low-fat/high-carbohydrates diet is causally related to breast cancer ${ }^{16}$.

However, several studies support a protective role for MUFA intake ${ }^{17,18}$ and olive oil consumption ${ }^{7-10}$ on breast cancer risk. The results have been linked to the theory that monounsaturated olive oil's fatty acids structure hinders free radical-initiated peroxidation.

For example, in a Greek case-control study the OR for the highest consumption of olive oil relative to the 'once-a-day' reference category was 0.75 (CI 95\% $0.57-0.98)^{8}$. Similar results were observed in a case-control study carried out in Italy $(\mathrm{OR}=0.89$ per any increment of $30 \mathrm{~g}$ in olive oil consumption $)^{10}$.

In a multi-centre case-control study in five regions of Spain, total fat and MUFA intakes and olive oil consumption ${ }^{7}$ were evaluated, with only the latter being inversely associated with breast cancer (OR $=0.66, \quad 95 \%$ CI 0.46-0.97 for the highest quartile of consumption).

EURAMIC, a multi-centre case-control study carried out in 11 European countries, reported a strong and protective effect of oleic acid intake, the most frequent monounsaturated fatty acid contained in olive oil, but only in Spain $^{18}$. Consequently, it has been postulated that oleic acid intake is a proxy for other olive oil components.

Specifically, current interest is centered on polyphenolic compounds of extra-virgin olive oil (hydroxytyrosol, oleuropeine, flavonoids, and catechines) that have demonstrated antioxidant properties in laboratory experiments ${ }^{19,20}$.

Breast and other cancer mortality rates have incremented in the Southern European countries in the last years. These changes correlate with an increase in the consumption of milk, meat and animal fat products. In Spain, it has been accompanied with a decrease in olive oil and an increase of other vegetables oils consumption ${ }^{21}$.

Breast cancer incidence and mortality rates are even higher in the Canary Islands. Whereas the incidence is around 48 cases per $10^{5}$ person-years in Spain, the value increases to 53 cases in Las Palmas, one of the two provinces of the Archipelago. However, the gap between the Canary Islands and the rest of Spain has been shortened in the last years. A possible explanation could be the increment in olive oil consumption observed in the Canary Islands: 17000 tonnes in 2002 from 8000 tonnes in 1992, when a new and specific regulation for supplies was implemented (REA, Régimen Específico de Abastecimiento). The REA incentives the import of products not available in the islands, including olive oil ${ }^{22}$, allowing for an effective nutritional promotion.

Our results support the protective role of olive oil suggested by other studies carried out among Mediterranean populations. Public health recommendations should focus on promoting and facilitating olive oil consumption through political, economical, and social strategies.

\section{Acknowledgements}

This study was partially granted by the Spanish Ministry of Health (Fondo de Investigaciones Sanitarias, FIS 98/0917) and the Canary Islands Department of Health (Fundación Canaria de Investigación y Salud, FUNCIS 41/98). Dr García-Segovia's stay at the University of Las Palmas de Gran Canaria was supported by the Research Exchange Program (PPI-00-03) of the Polytechnic University of Valencia.

\section{References}

1 Willett WC. Dietary fat and breast cancer. In: Willett WC, ed. Nutritional Epidemiology, 2nd ed. New York: Oxford University Press, 1998; 377-413.

2 Hunter DJ, Spiegelman D, Adami H-O, Beeson L, van den Brandt PA, Folsom AR, et al. Cohort studies of fat intake and the risk of breast cancer - a pooled analysis. New England Journal of Medicine 1996; 334: 356-61.

3 Holmes MD, Hunter DJ, Colditz GA, Stampfer MJ, Hankinson SE, Speizer FE, et al. Association of dietary intake of fat and fatty acids with risk of breast cancer. Journal of the American Medical Association 1999; 281: 914-20.

4 Smith-Warner SA, Spiegelman D, Adami H-O, Beenson WL, van den Brandt PA, Folsom AR, et al. Types of dietary fat and breast cancer: a pooled analysis of cohort studies. International Journal of Cancer 2003; 92: 767-74.

5 Estève J, Kricker A, Ferlay J, Parkin DM. Facts and Figures of Cancer in the European Community. Lyon: International Agency for Research on Cancer, 1993.

6 Trichopoulou A, Lagiou P, Kuper H, Trichopoulos D. Cancer and Mediterranean dietary traditions. Cancer Epidemiology, Biomarkers \& Prevention 2000; 9: 869-73.

7 Martín-Moreno JM, Willett WC, Gorgojo L, Banegas JR, Rodríguez-Artalejo F, Fernández-Rodríguez JC, et al. Dietary fat, olive oil intake and breast cancer risk. International Journal of Cancer 1994; 58: 774-80.

8 Trichopoulou A, Katsouyanni K, Stuver S, Tzala L, Gnardellis C, Rimm E, et al. Consumption of olive oil and specific food groups in relation to breast cancer risk in Greece. Journal of the National Cancer Institute 1995; 87: 110-6.

9 Morales Suárez-Varela M, Jiménez López MC, Almenar Cubells D, Llopis González A. Effect of the ingestion of food 
and gynecologic risk factors on breast cancer risk in Valencia. Nutrition Hospitalaria 1998; 13: 325-9.

10 La Vecchia C, Negri E, Francheschi S, Decarli A, Giacosa A, Lipworth L. Olive oil, other dietary fats, and the risk of breast cancer (Italy). Cancer Causes \& Control 1995; 6: 545-50.

11 Trichopoulou A, Lagiou P. Methodology for the Exploitation of Household Budget Survey Food Data Availability in Six European Countries. Luxembourg: Office for Official Publications of the European Communities, 1998.

12 Martín-Moreno JM, Boyle P, Gorgojo L, Maisonneuve P, Fernández-Rodríguez JC, Salvini S, et al. Development and validation of a food frequency questionnaire in Spain. International Journal of Epidemiology 1993; 22: 512-9.

13 Mataix J, Mañas M, Martínez de Vitoria E. Tabla de composición de alimentos españoles, 3rd ed. Granada: Universidad de Granada, 1998.

14 Willett WC. Issues in analysis and presentation of dietary data. In: Willett WC, ed. Nutritional Epidemiology, 2nd ed. New York: Oxford University Press, 1998; 321-46.

15 Willett WC, Stampfer MJ. Implications of total energy intake for epidemiologic analysis. In: Willett WC, ed. Nutritional Epidemiology, 2nd ed. New York: Oxford University Press, 1998; 273-301.

16 Hunter DJ, Willett WC. Nutrition and breast cancer. Cancer Causes E Control 1996; 7: 56-68.
17 Landa MC, Frago N, Tres A. Diet and the risk of breast cancer in Spain. European Journal of Cancer Prevention 1994; 3: 313-20.

18 Simonsen NR, Fernández-Crehuet Navajas J, Martín-Moreno JM, Strain JJ, Huttunen JK, Martin BC, et al. Tissue stores of individual monounsaturated fatty acids and breast cancer: the EURAMIC study. European community multicenter study on antioxidants, myocardial infarction, and breast cancer. American Journal of Clinical Nutrition 1998; 68: 134-41.

19 Caruso D, Berra B, Giavarini F, Cortesi N, Fedeli E, Galli G. Effect of virgin olive oil phenolic compounds on in vitro oxidation of human low density lipoproteins. Nutrition, Metabolism, and Cardiovascular Diseases 1999; 9: 102-7.

20 Fitó M, Covas MI, Lamuela-Raventós R, Vila J, Torrents J, Marrugat J. Protective effect of olive oil and its phenolic compounds against low density lipoprotein oxidation. Lipids 2000; 35: 633-8.

21 Prieto-Ramos F, Serra-Majem Ll, La Vecchia C, Ramón JM, Tresserras R, Salleras L. Mortality trends and past and current dietary factors of breast cancer in Spain. European Journal of Epidemiology 1996; 12: 141-8.

22 Serra-Majem Ll, Cabrera-León A, Sierra-López A. Conclusiones de la Encuesta de Nutrición de Canarias (1997-98). Bases para una política de nutrición en Canarias. Archivos Latinoamericanos de Nutricion 2000; 50(Suppl. 1): 62-70. 